\title{
BMJ Open Pain management for chronic musculoskeletal conditions: the development of an evidence-based and theory-informed pain self-management course
}

\author{
Dawn Carnes, ${ }^{1}$ Kate Homer, ${ }^{1}$ Martin Underwood, ${ }^{2}$ Tamar Pincus, ${ }^{3}$ \\ Anisur Rahman, ${ }^{4}$ Stephanie J C Taylor ${ }^{1}$
}

To cite: Carnes D, Homer K, Underwood M, et al. Pain management for chronic musculoskeletal conditions: the development of an evidence-based and theoryinformed pain self-management course. BMJ Open 2013;3:e003534. doi:10.1136/bmjopen-2013003534

- Prepublication history for this paper is available online To view these files please visit the journal online (http://dx.doi.org/10.1136/ bmjopen-2013-003534).

Received 5 July 2013 Revised 7 October 2013 Accepted 9 October 2013

CrossMark

For numbered affiliations see end of article.

Correspondence to Dr Dawn Carnes; d.carnes@qmul.ac.uk

\section{ABSTRACT}

Objective: To devise and test a self-management course for chronic pain patients based on evidence and underpinned by theory using the Medical Research Council (MRC) framework for developing complex interventions.

Design: We used a mixed method approach. We conducted a systematic review of the effectiveness of components and characteristics of pain management courses. We then interviewed chronic pain patients who had attended pain and self-management courses. Behavioural change theories were mapped onto our findings and used to design the intervention. We then conducted a feasibility study to test the intervention.

Setting: Primary care in the inner city of London, UK. Participants: Adults (18 years or older) with chronic musculoskeletal pain.

Outcomes: Related disability, quality of life, coping, depression, anxiety, social integration and healthcare resource use.

Results: The systematic reviews indicated that group-based courses with joint lay and healthcare professional leadership and that included a psychological component of short duration ( $<8$ weeks) showed considerable promise. The qualitative research indicated that participants liked relaxation, valued social interaction and course location, and that timing and good tutoring were important determinants of attendance. We used behavioural change theories (social learning theory and cognitive behaviour approaches (CBA)) to inform course content. The course addressed: understanding and accepting pain, mood and pain, unhelpful thoughts and behaviour, problem solving, goal setting, action planning, movement, relaxation and social integration/ reactivation. Attendance was $85 \%$; we modified the recruitment of patients, the course and the training of facilitators as a result of testing.

Conclusions: The MRC guidelines were helpful in developing this intervention. It was possible to train both lay and non-psychologists to facilitate the courses and deliver CBA. The course was feasible and well received.
Strengths and limitations of this study

The approach enabled us to consider and integrate fidelity assessment.

- We were able to modify recruitment processes and the course to accommodate patient needs.

- We used the feasibility study to train the team and engage new networks for the main trial

- The approach was resource intensive and lengthy but contributed to an efficient trial.

\section{INTRODUCTION}

Chronic musculoskeletal conditions are costly and burdensome to individuals and the society. ${ }^{1}$ Point estimates of the prevalence of chronic musculoskeletal pain range from $46 \%$ to $76 \% .^{2}$ Despite an increased understanding of the factors contributing to the development of chronic pain, there has been little improvement in how successfully it is treated and managed. ${ }^{3}$ Treatment centres around pharmaceutical agents and physiotherapy. More complex interventions such as pain management programmes delivered by multidisciplinary teams and self-management courses delivered by lay people with chronic pain are also used to address the complexity of living with and managing chronic pain. ${ }^{4-6}$ The UK Department of Health and The Health Foundation have invested in the implementation of lay-led (ie, peer-led) self-management training courses through the Expert Patients Programme (EPP) ${ }^{6} \quad 7^{5}$ and the cocreating health initiative that aims to help people help themselves. ${ }^{8}$ The available evidence, however, suggests that it may not reduce healthcare resource use as expected ${ }^{9-11}$ and that there are only modest short-term beneficial effects on other outcomes. Very few studies have examined the long-term effects. ${ }^{10} 11$ 
In response to the paradox of continued government support of self-management programmes and equivocal evidence of effectiveness, the COping with persistent Pain, Effectiveness Research into Self-management (COPERS) study was commissioned by the UK National Institute of Health Research as a 5-year programme grant to improve the self-management of chronic pain.

Our aim was to design and test a practical and acceptable self-management intervention for chronic musculoskeletal pain.

This study illustrates how the Medical Research Council (MRC) framework for developing complex intervention can be implemented and used to develop interventions. ${ }^{12}$ We used the recommended approach for developing and designing this new intervention, which consisted of three phases

I. Identifying the evidence base,

II. Identifying appropriate theory to inform and model the design of the intervention,

III. Feasibility testing the intervention.

The first two projects informed the design of a pain self-management course, which we then pilot tested.

\section{Phase I: Identifying the evidence base}

We conducted two systematic reviews (SRs) to identify effective components and characteristics of pain management courses (SR1) and predictors, mediators and moderators of outcome in pain management courses (SR2). The methods and results are presented in detail elsewhere. ${ }^{13}{ }^{14}$ Additionally, we did a qualitative study (QS) of people living with chronic pain.

We searched relevant databases including: MEDLINE, CINAHL, AHMED and PsychInfo from January 1994 to April 2009 for randomised controlled trials (RCTs) and SRs of self-management interventions. We defined selfmanagement programmes as structured, taught or selftaught courses with distinct components principally aimed at patients (rather than carers) with the goal of improving the participants' health status or quality of life by teaching them skills to apply to everyday situations. To be considered a 'programme' (which implies more than one component), the intervention had to contain at least two of the following components: psychological components (such as behavioural or cognitive therapy), mind-body therapies (such as relaxation, meditation or guided imagery), physical activity (any form of exercise), material on lifestyle (such as dietary advice and sleep management) and pain education (such as understanding their condition and how to take medication effectively).

We characterised the interventions according to: type of delivery (group, individual, mixed or remote (eg, web based)), type of tutor (healthcare professional, lay or a combination of tutors), setting (medical (ie, hospital, physician office or primary care), community or work based), duration (more or less than 8 weeks) and number of different components.
We examined the following outcomes: pain intensity, physical function, general mental health, depression, anxiety, social function, healthcare use, global health measures, quality of life and self-efficacy, but only examined outcome measures with published evidence of validity and reliability. We grouped outcomes into three follow-up intervals: short term $(<4$ months $)$, medium term (4-8 months) and long term ( $>8$ months).

We used random effects model meta-analysis to generate standardised mean differences and grouped data according to the presence or absence of course characteristics or components. We looked for patterns of clinically important and statistically significant differences between groupings across different outcomes and follow-up intervals.

\section{Effective components and characteristics of pain management courses (SR1)}

Overall, the literature indicated that the strongest evidence for pain outcomes was for group self-management programmes led by healthcare professionals while lay-led courses appeared to benefit participants' selfefficacy (see table 1). ${ }^{13}$

The duration of courses did not appear to significantly influence their reported effectiveness and the setting had little impact on the outcome. Interventions including each of the components we tested (except mind body components) showed beneficial effects. Psychological components showed the most benefit. Increasing the number of components did not improve the overall benefit. Overall, our analysis provided some evidence for the use of short, group-delivered courses in convenient settings that have healthcare professional input (more detailed information can be accessed via reference 13).

\section{Predictors, mediators and moderators of outcome in pain management courses (SR2) ${ }^{14}$}

We identified papers that included analyses of predictors, moderators or mediators. We did meta-regression analyses using the standardised mean difference and estimated the precision of associations. ${ }^{15}$

We found strong evidence that self-efficacy and depression at baseline predicted outcome and strong evidence that self-efficacy and potentially pain-catastrophising and physical activity mediated outcome from selfmanagement programmes for chronic musculoskeletal pain. There were no data on moderators of treatment. ${ }^{14}$

\section{Qualitative study}

We conducted a phenomenological qualitative interview and focus group study. For the interview study, we purposively sampled course participants by gender, age and high-course and low-course attendance from two EEP providers and one pain management course provider, and for the focus groups we recruited a convenience sample of experts from those who had recently published in this field and tutors from two local EPP providers. We carried out in-depth interviews with 16 chronic 
Table 1 Key findings and subsequent recommendations for course design

\section{Key finding from phases I and II}

Group delivery appears to be effective (SR1)

Networking with others popular feature of SM courses (QS)

Most evidence to support professional tutors (SR1)

Mixed professional and lay tutor-led course also effective (SR1)

Medical and community settings associated with effective courses (SR1)

Convenience of courses important to participants (QS)

Courses longer than 8 weeks were no more effective than courses under 8 weeks (SR1)

SM Interventions with psychological components were more effective than usual care (SR1)

Increased number of components were not associated with bigger effect sizes (SR1)

Little evidence to support mind body therapy components (SR1)

Increasing self-efficacy may mediate intervention (SR2)

Increasing physical activity may mediate intervention (SR2)

Patient resistance to concept of exercise but not general activity (QS)

Depression at baseline may be a predictor for poorer outcomes (SR2)

Concerns of attendees about what happens after the course is completed (QS)

Reduction in activities common in chronic MSK pain patients (QS)

Isolation common in chronic MSK pain patients (QS)

Other key considerations influencing course design

Adult educationalists advised that to be interesting and effective the course should employ multiple media and modalities, be delivered in 20-min bites and encourage experiential learning

Attrition from self-management courses running over

6-8 weeks known to be a problem

Expert professional input may be useful or appealing to participants

Reproducibility and fidelity of the intervention

\section{How this finding influenced course design (influences on main trial shown in brackets)}

Group intervention

Groups to be led by a combination of a lay and a professional tutor

Courses to be held in convenient community or health centre settings

\section{Shorter duration course}

Principal component of new intervention to be psychological

Relaxation to be control intervention in main trial. Relaxation was included because participants liked it and to match exposure with the control (QS)

Course should aim to promote self-efficacy

We decided against a large physical activity component in the course but include taster activities (possible hobbies)

Course covers depression and encourages people who feel they may be depressed to discuss this with their doctor Follow-up session at 2 weeks

Inclusion of "taster" activity sessions in the course

Have plenty of time for socialising

Inclusion of role play, filmed material, small group exercises, exercises for pairs, active listening exercises, brainstorming, etc

Course run over 3 days in a single week

Expert professional input delivered by DVD for economy

Development of a course manual and training package pain self-management course participants (11 were female, 7 were 45 years or over, 10 were white, 6 were of South Asian origin and 10 people had attended half or more of a course). We convened two focus groups, one with self-management 'experts' $(n=5)$ and another with course tutors $(n=5)$. Topics discussed included referrals attendance, course content, course delivery issues and expectations. We used a thematic framework approach to analyse the data and identified key themes and subthemes relevant to devising a new pain self-management course. Participants identified six key areas that they felt their treatment for their chronic pain should address; it describes the participant needs and expectations (table 2). We tried to incorporate these needs and expectations as much as possible into the course. While we could not achieve some things by running a course, we aimed to give participants the skills to realistically assess their needs and show them how to achieve them.

We noted that the patients with chronic musculoskeletal pain whom we interviewed made positive comments about the courses they attended and had particular traits. They were prepared to be socially engaged; they were motivated prior to the course and took up new activities (not necessarily exercise related) after the course. Participants liked the social element and the relaxation components of the course. Good course facilitation and social support cemented their experience. Those with a low mood, poor social skills and unwillingness to change/reflect seemed less likely to engage with these types of courses. 
Phase II: Identifying appropriate theory to inform and model the design of the intervention

We searched the literature and spoke to key experts on behavioural change theory and models of persisting pain. We considered the following psychological theoretical models and learning and behaviour modification techniques: social cognitive ${ }^{16}{ }^{17}$ and cognitive behavioural theory, ${ }^{18}{ }^{19}$ including psychological flexibility (acceptance and commitment therapy, ie, the acceptance of internal experiences or things that cannot be changed countered by behavioural change techniques that are designed to reorientate people towards meaningful activity, ${ }^{20} 21$ theory of planned behaviour and reasoned action $^{22-24}$ (including emotional rationalisation) and health belief models. In addition, we looked at attention control techniques ${ }^{25}$ and physical movement to underpin and inform our intervention. Figure 1 illustrates the relationship between theory and course design.

We established a patient working group to devise an acceptable and appropriate intervention that reflected the evidence we had obtained and the theories we had identified as appropriate.

As recommended by the MRC guidelines, we considered patient pathways through the self-management programme, as well as the likely action and interaction of the different components on outcomes in an attempt to model the impact and effect of our intervention. ${ }^{12}$ We convened a 'consensus' group of two patients, three clinicians (general practitioner (GP) and two clinical psychologists), four researchers and one commissioner to agree on the outcomes we wanted the intervention to affect and the appropriate measurement tools. They were improved function despite pain, 'better' healthcare resource use, reactivation into society, more selfconfidence in managing pain, better coping and reduced anxiety and depression. The measurement tools were selected and tested in the feasibility study (a sample of which is shown in table 3). We assessed the behavioural change theories relevant to a new intervention and identified individual behavioural change techniques for different learning outcomes and the different components of a course (table 4). We also used a taxonomy of behavioural change techniques developed by Abraham and Michie ${ }^{26}$ to describe the techniques we adopted to promote positive behavioural change in self-management groups.

The courses also allowed opportunities for people to learn and try new behaviours in an appropriate environment.

Table 4 shows our rationale for mapping and modelling theory to behavioural change techniques and the methods used by facilitators throughout the courses. The final column describes the behavioural change techniques that were used throughout the courses. While some sessions required facilitators to employ techniques focusing on providing feedback, other sessions provided instruction to promote behavioural change and yet others allowed participants to try out techniques within the 'safety' of the learning environment and the

Table 2 Qualitative interview study: needs and expectations important to participants

\begin{tabular}{|c|c|c|c|c|c|}
\hline $\begin{array}{l}\text { Functional } \\
\text { (practical daily } \\
\text { living requirements) }\end{array}$ & $\begin{array}{l}\text { Physical } \\
\text { (equipment aids } \\
\text { and help) }\end{array}$ & $\begin{array}{l}\text { Emotional (dealing } \\
\text { with frustration, } \\
\text { anger, boredom, } \\
\text { isolation, } \\
\text { depression) }\end{array}$ & $\begin{array}{l}\text { Social (social } \\
\text { networking, } \\
\text { relationships with } \\
\text { partners, family and } \\
\text { friends) }\end{array}$ & $\begin{array}{l}\text { Economic } \\
\text { (financial support, } \\
\text { benefits etc, } \\
\text { work-related } \\
\text { issues) }\end{array}$ & $\begin{array}{l}\text { Medical (pain } \\
\text { and drug related) }\end{array}$ \\
\hline Activities of daily & Mobility aids & Mood modification & Making new friends & Financial support & Pain reduction \\
\hline $\begin{array}{l}\text { living Being able to } \\
\text { cook, shop clean } \\
\text { etc. }\end{array}$ & $\begin{array}{l}\text { Provision of } \\
\text { equipment to } \\
\text { help move and } \\
\text { achieve tasks }\end{array}$ & $\begin{array}{l}\text { Changing and } \\
\text { managing feelings } \\
\text { better. Dealing with } \\
\text { emotions }\end{array}$ & $\begin{array}{l}\text { Meeting new people, } \\
\text { finding new friends }\end{array}$ & $\begin{array}{l}\text { Benefit payments } \\
\text { from the state }\end{array}$ & $\begin{array}{l}\text { Better knowledge } \\
\text { of drugs and how } \\
\text { to take them } \\
\text { Better prescribing } \\
\text { of more effective } \\
\text { drugs }\end{array}$ \\
\hline Personal hygiene & Home help & Behavioural change & Improving relationships & Special & Reduction in side \\
\hline $\begin{array}{l}\text { Being able to dress } \\
\text { and wash } \\
\text { independently }\end{array}$ & $\begin{array}{l}\text { Physical help } \\
\text { from others to do } \\
\text { things }\end{array}$ & $\begin{array}{l}\text { Learning how to do } \\
\text { things better within } \\
\text { the context of pain }\end{array}$ & $\begin{array}{l}\text { Communication, } \\
\text { understanding, } \\
\text { recognition of condition }\end{array}$ & $\begin{array}{l}\text { allowances } \\
\text { Disability parking } \\
\text { permits }\end{array}$ & $\begin{array}{l}\text { effects of drugs } \\
\text { Nausea, } \\
\text { vomiting, } \\
\text { diarrhoea and } \\
\text { constipation }\end{array}$ \\
\hline \multirow{3}{*}{$\begin{array}{l}\text { Looking after } \\
\text { others } \\
\text { Being able to } \\
\text { manage children } \\
\text { and partners better }\end{array}$} & & $\begin{array}{l}\text { Pain management } \\
\text { Learning new ways }\end{array}$ & $\begin{array}{l}\text { Helping others } \\
\text { understand living with }\end{array}$ & Return to work & $\begin{array}{l}\text { Access to 'non } \\
\text { medical' }\end{array}$ \\
\hline & & to manage pain & pain & & $\begin{array}{l}\text { treatment } \\
\text { Massages, } \\
\text { acupuncture, gym } \\
\text { memberships }\end{array}$ \\
\hline & & $\begin{array}{l}\text { Having someone to } \\
\text { listen and talk to }\end{array}$ & $\begin{array}{l}\text { Finding a hobby/ } \\
\text { distraction from pain }\end{array}$ & & $\begin{array}{l}\text { Getting GP } \\
\text { support }\end{array}$ \\
\hline
\end{tabular}




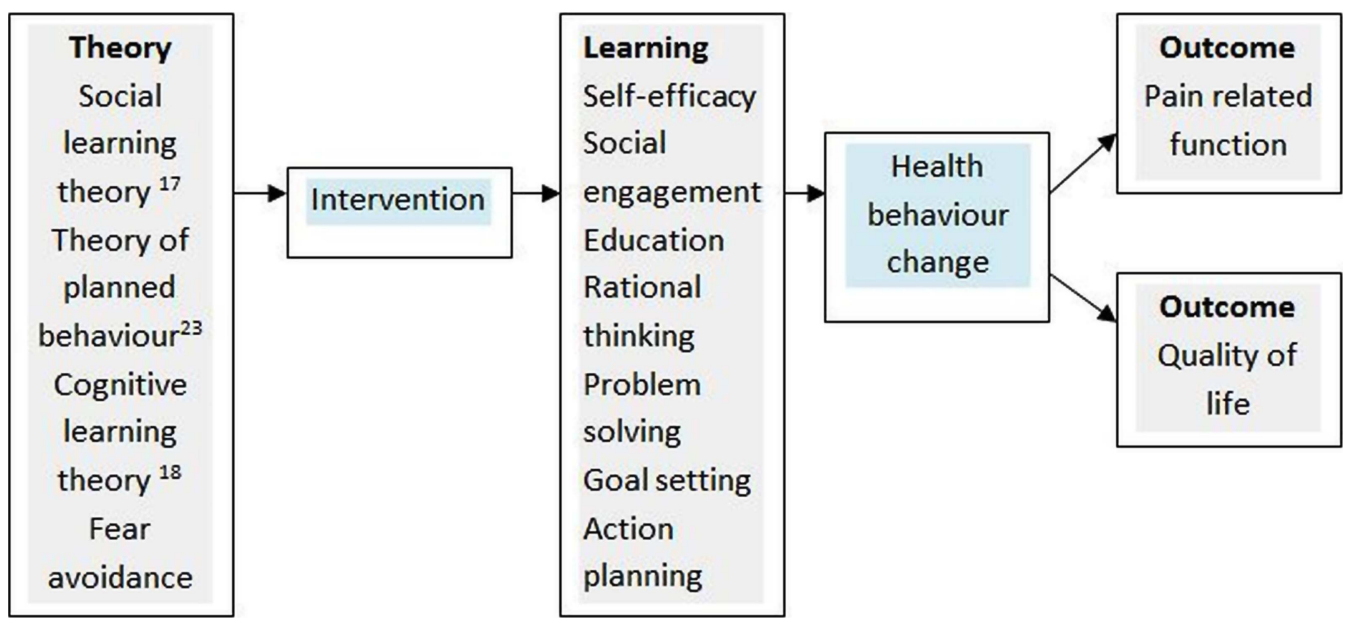

Figure 1 Model of relationship between theory and intervention development.

group. The techniques employed by facilitators were often dependent on the needs of the participants and the groups and therefore are utilised as necessary and when required in each individual session. No negative or coercive behavioural change techniques were recommended or used as part of the courses. We decided that the components of the course should include: psychological concepts using cognitive behavioural (http:// www.babcp.com/) approaches to managing chronic pain (these covered: acceptance, attention control, goal setting and action planning, recognising unhelpful thinking and behaviours); the course also covered communication skills, relationships, promoting better sleep, medical education, social networking, hobbies and activities, posture and movement, breathing, relaxation and visualisation and guided imagery. Our QS indicated that patient understanding about pain was limited, so we therefore decided to include an educational DVD with a pain consultant answering common questions from patients with chronic pain. The structure of the course we piloted is shown in table 5 .

\section{Course}

The findings from the SRs and the QS informed the design of the new intervention (table 1). The final course structure and content included a mix of theoretical concepts and psychological, behavioural, educational and physical techniques. Our qualitative research and evidence reviews identified a variety of components, characteristics and functions to accommodate in the selfmanagement course, hence the eclectic design.

We designed a group course to be facilitated by a healthcare professional (a psychologist, physiotherapist, chiropractor, osteopath, occupational therapist or GP) and a lay person with chronic pain with prior experience in small group facilitation (eg, a course facilitator on the EPP). The course was structured to be delivered over three short days in 1 week (10:00-14:45), with a $2 \mathrm{~h}$ follow-up session 2 weeks later. We also designed a 2-day training programme for all potential facilitators. All courses were to be held in a convenient, accessible location for study participants.

\section{Phase III: assessing the feasibility of the intervention (COPERS trial ISRCTN 24426731) \\ Method}

We used an uncontrolled pilot study approach to test the feasibility of delivering the intervention and the receipt of the intervention.

Table 3 Summary baseline data describing the population recruited (mean (SD))

\begin{tabular}{|c|c|c|c|c|c|c|c|}
\hline Data & $\begin{array}{l}\text { Pain } \\
\text { intensity } \\
\text { Scale } \\
0-10\end{array}$ & EQ5d & $\begin{array}{l}\text { PSEQ } \\
\text { Scale } \\
0-60\end{array}$ & $\begin{array}{l}\text { HADS } \\
\text { Anxiety } \\
\text { Scale } \\
1-21\end{array}$ & $\begin{array}{l}\text { HADS } \\
\text { Depression } \\
\text { Scale } \\
1-21\end{array}$ & $\begin{array}{l}\text { CPAQ } \\
\text { Scale } \\
0-120\end{array}$ & $\begin{array}{l}\text { HEIQ } \\
\text { Scale } \\
5-20\end{array}$ \\
\hline B'line $(n=43)$ & $6.7(2.1)$ & $0.23(0.4)$ & 22.5 (12.7) & $11.3(4.1)$ & $9.4(3.8)$ & 46.7 (17.3) & $12.8(3.1)$ \\
\hline$F-U(n=25)$ & $6.3(2.2)$ & $0.31(0.4)$ & $30.2(13.1)$ & $10.2(3.8)$ & $8.8(4.1)$ & $54.1(18.02)$ & $13.1(3.5)$ \\
\hline
\end{tabular}

Numerical rating scale pain: $0-10=$ worst pain imaginable, Euroqol-Quality of life indicator (EQ5D), UK norm healthy males/females 4049 years $0.89 / 0.87$ and $50-59$ years $0.8 / 0.82$ ( 0 death). ${ }^{27}$ Pain self-efficacy questionnaire (PSEQ) scale: $0-60=$ completely confident, ${ }^{28}$ hospital anxiety and depression scale (HADS), scale: 0-7 'normal', 8-10 borderline, 11-21 'abnormal'. ${ }^{29}$ Chronic pain and acceptance questionnaire scale (CPAQ): $120-0=$ not coping at all, ${ }^{30}$ Health education involvement questionnaire (HEIQ) Higher scores indicate a better social life. ${ }^{31}$ 
Table 4 Theories, therapies and cognitive and behavioural techniques influencing the design of the course

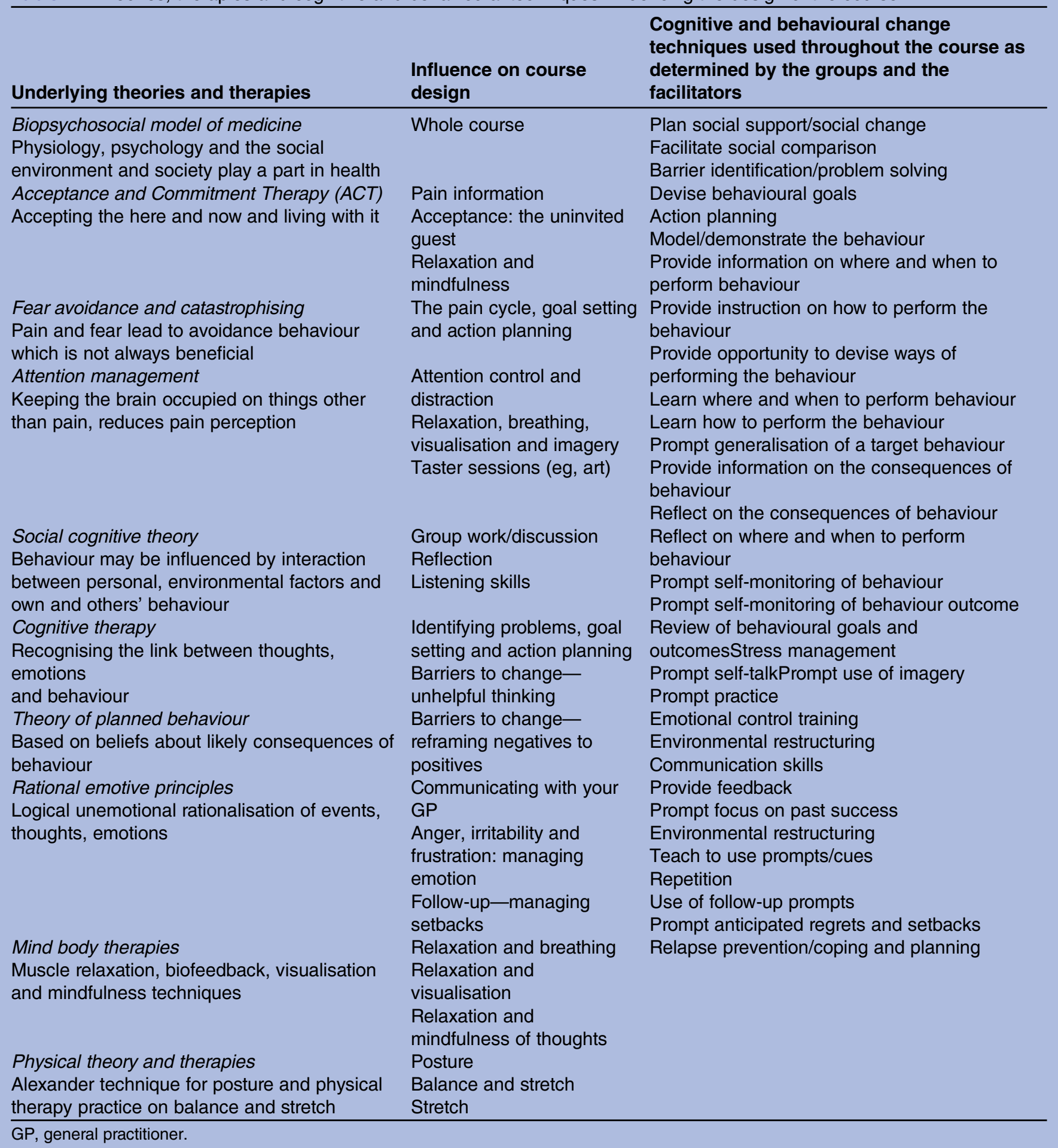

\section{Participants}

Adults (18 years and over) included those with persistent musculoskeletal pain (pain in their muscles or joints lasting longer than the normal expected healing time of 3 months) who were physically and mentally able to attend a community-based group course. We excluded those who had any other more serious comorbidity than their pain (such as terminal illness, cancer, uncontrolled addictions or other mental health issues).
All patients were required to be fluent in English as this was a group-based course reliant on discussion and interaction.

\section{Sample size}

We estimated that six courses of 8-10 people would be sufficient to evaluate the course; we aimed to recruit around 60-80 participants allowing for dropouts. 
Table 5 Pilot course overview and final course

\begin{tabular}{|c|c|c|}
\hline Day & Sessions & Content of sessions \\
\hline 1 & 1. Introduction and & Session 1: Introduction \\
\hline \multirow{7}{*}{$\begin{array}{l}\text { Living and dealing with } \\
\text { pain }\end{array}$} & understanding pain and acceptance & Session 2: Pain information \\
\hline & & Session 3: Acceptance: the uninvited guest \\
\hline & Lunch & \\
\hline & Taster activity & Art \\
\hline & 2. Mind, mood and pain & $\begin{array}{l}\text { Session 4: Pain, when is it bearable and when is it not? } \\
\text { Session 5: The pain cycle }\end{array}$ \\
\hline & \multirow{2}{*}{$\begin{array}{l}\text { 3. Movement and posture and } \\
\text { relaxation }\end{array}$} & Session 6: Movement and posture \\
\hline & & Session 7: Breathing and relaxation (focusing the mind) \\
\hline \multirow{8}{*}{$\begin{array}{l}2 \\
\text { Doing something about } \\
\text { your life with pain }\end{array}$} & \multirow{3}{*}{$\begin{array}{l}\text { 4. Dealing with unhelpful, negative } \\
\text { thoughts and barriers to change }\end{array}$} & Session 8: Reflections from day one \\
\hline & & $\begin{array}{l}\text { Session 9: Identifying problems, goal setting and action } \\
\text { planning }\end{array}$ \\
\hline & & Session 10: Unhelpful thinking and automatic thoughts \\
\hline & \multicolumn{2}{|r|}{ 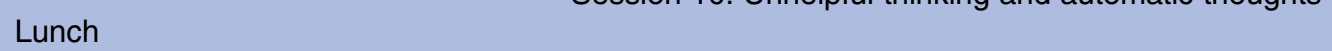 } \\
\hline & Taster activity & Hand massage \\
\hline & 5. Making pain more manageable & $\begin{array}{l}\text { Session 11: Barriers to change, challenging unhelpful } \\
\text { thoughts. Pros and cons of chronic pain and reframing } \\
\text { Session 12: Attention control and distraction } \\
\text { Session 13: Identifying things that make pain more } \\
\text { manageable }\end{array}$ \\
\hline & \multirow[t]{2}{*}{ 6. Movement and Relaxation } & Session 14: Movement and balance \\
\hline & & Session 15: Breathing, relaxation and visualisation \\
\hline \multirow{9}{*}{$\begin{array}{l}3 \\
\text { Communication and } \\
\text { relationships }\end{array}$} & \multirow{5}{*}{$\begin{array}{l}\text { 7. Communication skills } \\
\text { and relationships }\end{array}$} & Session 16: Reflections from day 2 \\
\hline & & Session 17: Communication with health professionals \\
\hline & & Session 18: Communication and listening \\
\hline & & Session 19: Anger, irritability, frustration \\
\hline & & Session 20: Intimacy (rejected after testing) \\
\hline & Lunch & Introduce idea of 'buddying' (rejected after testing) \\
\hline & Taster activity & Craft (rejected after testing; added volunteering instead) \\
\hline & \multirow[t]{2}{*}{ 9. Movement and relaxation } & Session 21: Movement and stretch \\
\hline & & Session 22: Relaxation and guided imagery \\
\hline 4 & \multirow[t]{2}{*}{ 10. The future } & Session 23: Reflections \\
\hline Follow-up & & Session 24: Managing setbacks \\
\hline
\end{tabular}

\section{Setting}

Inner London urban community in East London. We recruited patients from two local general practices, the Tower Hamlets Persistent Pain Service and the musculoskeletal physiotherapy service at Mile End Hospital. Participants were identified by clinicians from known regular patients and ad hoc from face-to-face consultations. We delivered the courses in community-based venues convenient for participants.

\section{Outcomes}

We used a number of outcome measures to test completion rates and acceptability. Questionnaire instruments are shown in table 3 .

\section{Follow-up}

Participants completed postal questionnaires at a baseline and at 3 months.

\section{Fidelity and facilitator training: adherence and competence}

We trained 15 facilitators to deliver the course. They underwent a 2-day training course and included six lay people with chronic pain and nine healthcare professionals (one chiropractor, three osteopaths, two physiotherapists, one psychologist, one occupational therapist and one GP). Three of these trained healthcare professionals were unable to facilitate courses due to work pressures.

We observed all the courses and wrote extensive field notes. In addition to collecting our outcome data, we asked for written feedback about the courses from the facilitators and the participants and also interviewed 13 participants. We collected data about attendance for every component of the course and reasons for nonattendance and non-participation.

\section{RESULTS}

We sent 518 invitation letters to people with chronic pain (335 were female); 68 people agreed to participate (13\% response rate), 8 withdrew without accepting a place, and 60 accepted a place on a course (33 were female). In 4 months, we delivered six courses with an average of seven participants per course. Overall, participants attended $85 \%$ of all sessions. 


\section{Participant feedback}

The overall satisfaction score $(0-5$ with five indicating most satisfied) was 4.2. The interview data revealed that participants most liked meeting other people with chronic pain and the relaxation sessions. Participants who attended few sessions (less than 1 day), or did not attend, reported that work commitments and being in a group were an issue, and that some poor facilitation affected their learning and pleasure. Some participants mentioned that they thought the intimacy session was too personal and they did not want to disclose this type of information to people they did not know well.

\section{Facilitator feedback}

This centred on the need for preparation and experience in facilitation and handling difficult situations. Observer feedback identified that there were some modules that needed to be amended, and that the intimacy session did not work well due to the reluctance of participants to discuss issues. In addition, the facilitators felt that the 'buddying-up' system (the facilitators created and provided the opportunity and time for group members to exchange contact details) should be instigated and initiated by the group themselves, not the facilitators, as some group members found the concept of buddying too intrusive. More handouts were suggested and facilitators needed more training in facilitation to make sure that they were confident. However, all facilitators felt that they improved as they progressed through the courses.

No serious adverse events occurred as a result of the intervention.

\section{Quantitative data}

Descriptive results from the baseline questionnaire showed that 53\% (23/43) of participants were female, modal age range was $41-50$ years (15 participants). Twenty-one people $(49 \%)$ regarded themselves as unemployed or as unable to work due to pain, 12 were employed, 5 were retired and 4 were looking after family at home.

\section{Baseline}

Overall, the profile of the participants at baseline suggested that they had above average pain (6.7 on a scale of $0-10)$ and rated their quality of life as low; also, they had high anxiety scores and were not coping well (table 3).

\section{Follow-up}

The follow-up response rate was $58 \%$. Participant, facilitator and researcher feedback suggested that the follow-up questionnaire length (94 questions) was too burdensome and therefore unacceptable for the main trial.

\section{Findings and recommendations to optimise the intervention and a trial protocol}

The course was feasible, acceptable to participants and deliverable. Participants were positive about the course and the content appeared to be meaningful to them. Attrition was very low over the three main days: participants attended an average $85 \%$ of the course. Attrition has been reported as an issue in other trials; one such trial (intervention arm $n=313$ ) using expert patient programmes over a 6 -week period showed a loss of $26 \%$ participants between referral and course attendance and $40 \%$ of participants attended three or less sessions overall, that is, $50 \%$ or less of the course sessions. ${ }^{11}$

The facilitation and group process may have optimised the learning process as discussion embedded participant thinking. All the course evaluation material suggested that good facilitation skills were crucial for positive participant perception. Comprehensive facilitator training is essential for courses to run effectively.

Recruitment to the study was difficult and conversion rates from invitation to course attendance were lower than we had hoped ( $13 \%$ of those invited), but were in line with other studies of this nature recruiting patients from primary care with chronic conditions. ${ }^{32-34}$ Despite this, we had sufficient interest from patients to run six courses and this feasibility study showed that there was a demand for learning about non-pharmacological approaches to managing pain. Procedures for future recruitment can be enhanced by increasing the number of invitations and devising and testing a comprehensive and inclusive electronic search strategy for patients with chronic pain. ${ }^{35}$ It is also quite likely that recruitment to the intervention would be higher outside the context of a research study.

Recruitment needs to be timed with the delivery of the intervention (ie, course dates which had to be planned in advance due to facilitator and accommodation availability). We estimated that an average lead time from identification of participant, screening for suitability by GP, sending invitation, receiving enquiries and interest, sending out and returning baseline questionnaires, randomisation and booking on a course takes around 8 weeks. Building rapport with participants from the outset is crucial to reduce loss of potential participants prior to being enroled, randomised and/or booked on a course.

In this pilot, participants reported poor quality of life, low self-efficacy to manage their chronic pain, relatively high levels of social isolation, poor coping and a tendency to anxiety and depression. Thus, secondary outcome measures need to reflect these health and social states. Our descriptive baseline data may explain why the 'buddying system' and the 'Intimacy session' from the course were too difficult for some participants to deal with. It may be that depression should be addressed with patients prior to, or in conjunction with, attending these types of courses.

The theory underpinning the decisions to include the variety of sessions and behavioural change techniques worked within the group learning environment; this has also been shown to be effective in other studies of chronic pain. ${ }^{33} 36$ The learning sequence we adopted enabled each session to build on the previous session, 
and in many cases the participants were able to predict the next phase of learning in advance. The learning and flow of information was pitched at a level where participants could follow the structure and understand the content. This was shown in the daily feedback sheets where we asked participants what they had learnt; their learning mapped well onto the learning objectives. The quotes below illustrate some of this.

it was shocking to think there is no cure for my pain but I suppose there isn't, otherwise I would have been given it by now

the 'unhelpful thinking'...they were all me, I will look out for these now, I've stuck them (the list of automatic thoughts) on my fridge door

the relaxation and the breathing really help me

I spend all day trying not to think about my pain but that's the worst thing I can do

The best part was meeting everyone

The participants valued the social interaction on the course highly; for some participants, it appeared to have an impact on self-esteem and confidence, for example, self comparison with others in less fortunate circumstances, perspective on life, distraction, laughter and release from boredom and isolation in some cases.

We found that it was possible to train both lay and non-psychologists to facilitate the courses and deliver cognitive behaviour approach. Delivery styles did vary and there is value in thorough training and evaluation of training and subsequent delivery of courses, embedding fidelity assessment from the outset to measure the adherence and competence of those delivering the intervention. We found that the course stood up to the inexperience of our facilitators to deliver an entirely new course; the content in terms of the discussions, information and handouts was robust enough to make an impression regardless of the delivery style. We recommend that inexperienced personnel are partnered with experienced personnel initially.

A by-product of testing the programme was staff training and development based on their experience of conducting the pilot. We also found that we built valuable networks and contacts, which was helpful for the main trial.

\section{CONCLUSION}

The MRC guidance for developing complex interventions enabled us to develop and test an evidence-based and theory-informed pain self-management course. The process enhanced the intervention and gave the study team confidence in the modified intervention and trial procedures and processes necessary to run a full effectiveness and cost effectiveness RCT efficiently. ${ }^{37}$
Author affiliations

${ }^{1}$ Centre for Primary Care and Public Health, Barts and The School of Medicine and Dentistry, Queen Mary University of London, London, UK

${ }^{2}$ Clinical Trial Units, Warwick Medical School, Coventry, UK

${ }^{3}$ Department of Psychology, Royal Holloway University of London, London, UK

${ }^{4}$ Department of Rheumatology, University College London, London, UK

Contributors DC wrote the first draft of the paper and managed all the development phases of the study. KH worked on all phases of the development and has contributed to and commented on the manuscript. MU and SJCT are the principal investigators on the project and provided oversight and guidance in all stages of the research and contributed to the manuscript. TP was involved in the systematic reviews and the theoretical development of the programme and has commented on the paper. AR developed and delivered the education component of the course and has commented on this paper.

Funding This paper presents independent research funded by the National Institute for Health Research (NIHR) under its Programme Grants for Applied Research scheme (RP-PG-0707-10189). The views expressed in this publication are those of the authors and not necessarily those of the NHS the NIHR or the Department of Health.

Competing interests None.

Ethics approval Ethics approval was granted by the East London and The City Research Ethics Committee Alpha (10//H0704/7). ISRCTN: 24426731 COPERS trial.

Provenance and peer review Not commissioned; externally peer reviewed.

Data sharing statement All additional data pertaining to this study will be published in a full NIHR report published by the funder.

Open Access This is an Open Access article distributed in accordance with the Creative Commons Attribution Non Commercial (CC BY-NC 3.0) license, which permits others to distribute, remix, adapt, build upon this work noncommercially, and license their derivative works on different terms, provided the original work is properly cited and the use is non-commercial. See: http:// creativecommons.org/licenses/by-nc/3.0/

\section{REFERENCES}

1. Lim SS, Vos T, Flaxman AD, et al. A comparative risk assessment of burden of disease and injury attributable to 67 risk factors and risk factor clusters in 21 regions, 1990-2010: a systematic analysis for the Global Burden of Disease Study. Lancet 2010;380:2224-60.

2. Parsons S, Breen A, Foster NE, et al. Prevalence and comparative troublesomeness by age of musculoskeletal pain in different body locations. Fam Pract 2007;24:308-16.

3. Croft $P$. Is life becoming more of a pain? BMJ 2000;320:1552-3.

4. Wanless D. Securing our future health: taking a long-term view-the Wanless Report. Department of Health, Stationery Office, 2002. http://www.dh.gov.uk/en/Publicationsandstatistics/Publications/ PublicationsPolicyAndGuidance/DH_4009293

5. Donaldson L. Expert patients usher in a new era of opportunity for the NHS. BMJ 2003;326:1279-80.

6. Department of Health. The expert patient: a new approach to chronic disease management for the 21st century. Department of Health Stationery Office, 2001. http://www.dh.gov.uk/en/Publicationsand statistics/Publications/PublicationsPolicyandGuidance/DH 4006801

7. Expert patient programme. http://www.expertpatients.co.uk/ (accessed 17 Jun 2013).

8. Health foundation UK, co-creating health initiative. http://www.health. org.uk/areas-of-work/programmes/co-creating-health/ (accessed 17 Jun 2013).

9. Griffiths C, Foster G, Ramsay J, et al. How effective are expert patient (lay led) education programmes for chronic disease? BMJ 2007;334:1254-6.

10. Foster G, Taylor SJ, Eldridge SE, et al. Self-management education programmes by lay leaders for people with chronic conditions. Cochrane Database Syst Rev 2007;(4):CD005108.

11. Kennedy A, Reeves D, Bower P, et al. The effectiveness and cost effectiveness of a national lay-led self care support programme for patients with long-term conditions: a pragmatic randomised controlled trial. J Epidemiol Community Health 2007;61:254-61. 
12. Craig $\mathrm{P}$, Dieppe $\mathrm{P}$, Macintyre $\mathrm{S}$, et al. Developing and evaluating complex interventions: new guidance. Medical Research Council, 2008.

13. Carnes D, Homer KE, Miles CL, et al. Effective delivery styles and content for self-management interventions for chronic musculoskeletal pain: a systematic literature review. Clin J Pain 2012;28:344-54.

14. Miles CL, Pincus $T$, Carnes $D$, et al. Can we identify how programmes aimed at promoting self-management in musculoskeletal pain work and who benefits? A systematic review of sub-group analysis within RCTs. Eur J Pain 2011;15:775.e1-11.

15. Upton G, Cook I. Oxford dictionary of statistics. Oxford: Oxford University Press, 2002.

16. Bandura A. Self-efficacy: toward a unifying theory of behavioral change. Psychol Rev 1977;84:191-215.

17. Bandura A. Social foundations of thought and action: a social cognitive theory. Pearson Education, 1986.

18. Beck JS. Cognitive therapy. The Guildford Press, 1995.

19. Leahy R. Cognitive therapy techniques: a practitioner's guide. New York: Guildford Press, 2003.

20. Hayes SC, Smith SX. Get out of your mind and into your life: the new acceptance and commitment therapy. Oakland, CA: New Harbinger Publications, 2005.

21. Hayes SC, Strosahl KD, Wilson KG. Acceptance and commitment therapy: an experiential approach to behavior change. New York: Guilford Press, 2004.

22. Ajzen I, Fishbein M. Belief, attitude, intention and behaviour: an introduction to theory and research (Addison-Wesley series in social psychology). Longman Higher Education, 1976.

23. Ajzen I, Fishbein M. Understanding attitudes and predicting social behavior. Pearson Education, 1980.

24. Kuhl J, Beckman J. eds. Action control: from cognition to behavior (Springer series in social psychology). Berlin: Springer-Verlag and Heidelberg: GmbH \& Co, 1985.

25. Morley S, Shapiro DA, Biggs J. Developing a treatment manual for attention management in chronic pain. Cogn Behav Ther 2004;33:1-11.
26. Abraham C, Michie S. A taxonomy of behavior change techniques used in interventions. Health Psychol 2008;27:379-87.

27. Kind $\mathrm{P}$, Hardman G, Macran S. UK population norms for EQ-5D. Discussion paper 172. University of York, Centre for Health Economics, 1999

28. Nicholas MK. The pain self-efficacy questionnaire: taking pain into account. Eur J Pain 2007:11:153-63.

29. Zigmond AS, Snaith RP. The hospital anxiety and depression scale. Acta Psychiatr Scand 1983;67:361-70.

30. McCracken LM, Vowles KE, Eccleston C. Acceptance of chronic pain: component analysis and a revised assessment method. Pain 2004:107:159-66.

31. University of Melbourne . Health Education Impact Questionnaire. http://www.crd.unimelb.edu.au/heiq/

32. UK BEAM Trial Team. United Kingdom back pain exercise and manipulation (UK BEAM) randomised trial: effectiveness of physical treatments for back pain in primary care. $B M J$ 2004;329:1377.

33. Lamb SE, Hansen Z, Lall R, et al. Group cognitive behavioural treatment for low-back pain in primary care: a randomised controlled trial and cost-effectiveness analysis. Lancet 2010;375:916-23.

34. Johnson RE, Jones GT, Wiles NJ, et al. Active exercise, education, and cognitive behavioral therapy for persistent disabling low back pain: a randomized controlled trial. Spine 2007;32:1578-85.

35. Foell J, Carnes D, Homer K, et al. Developing and implementing electronic search strategies to recruit patients with chronic musculoskeletal pain in primary care databases. Primary Health Care Res Dev 2013;May 24:1-10. doi:10.1017/S1463423613000248

36. Ostelo R, van Tulder MW, Vlaeyen JWS, et al. Behavioural treatment for chronic low-back pain. Cochrane Database Syst Rev 2005;(1):CD002014

37. Carnes $\mathrm{D}$, Underwood $\mathrm{M}$, Homer $\mathrm{K}$, et al. Effectiveness and cost effectiveness of a novel, group self-management course for adults with chronic musculoskeletal pain: study protocol for a multi-centre, randomised controlled trial (COPERS). BMJ Open 2013;3:e002492. 